\title{
Assessment of Computational Thinking Notions in Secondary School
}

\author{
Javier BILBAO, Eugenio BRAVO, Olatz GARCÍA, \\ Concepción VARELA, Carolina REBOLLAR \\ Applied Mathematics Department, Engineering School of Bilbao, \\ University of the Basque Country, \\ Plaza Ingeniero Torres Quevedo, 1 - 48013 Bilbao, Spain \\ javier.bilbaodehu.es; eugenio.bravodehu.es; olatz.garciadehu.es; \\ concepción.varela@ehu.es; carolina.rebollar@ehu.es
}

\begin{abstract}
New technological developments, the hyperconnectivity and globalization of the economy are raising important opportunities and challenges to the economy. The labour market must also address these opportunities and challenges, to evolve and accommodate future workers and businesses. The introduction of digital technologies in sectors of the economy allows devices and systems collaborate with each other and with other systems allowing to modify the products, processes and business models. The digitization of society and the economy poses challenges and creates opportunities for all sectors must adapt their processes, products and business models. Educational system cannot be left out of this future and new models like Computational Thinking (CT) can help achieve and better prepare future citizens. But when new skills and techniques such as CT are applied, it is necessary to evaluate them. In this paper a model for evaluating the skills and attitudes of CT for subjects of secondary education is presented.
\end{abstract}

Keywords: Computational Thinking, Informatics, Computer Science, ICT, education, digital competence, Secondary School, assessment.

\section{Introduction}

Labor market is constantly changing and today it is required that workers have the necessary training to not only use new technologies but to be part of the creation and development of them. In addition, schools must prepare our students for jobs that increasingly demand more skills in new technologies and computer and also for jobs that have not yet emerged, but where classic skills fall short for a good performance of tasks.

The necessity of knowledge in computing is essential in the global economy market, being a basic tool for competition in the majority of jobs.

Mark Weiser said in the early 1990s that ubiquitous computing names the third wave in computing, just now beginning. First were mainframes, each shared by lots of people. Now we are in the personal computing era, person and machine staring uneasily at each other across the desktop. Next comes ubiquitous computing, or the age of calm technology, when technology recedes into the background of our lives (Weiser, 1991; Weiser, 1993). 
But previous to students can use their computers to solve a problem, the problem itself and the ways in which it could be resolved must be understood. Computational Thinking (CT) competences help with these tasks. Computational Thinking involves solving problems, designing systems, and understanding human behavior, by drawing on the concepts fundamental to computer science. It includes a range of mental tools that reflect the breadth of the field of computer science (Weintrop et al. 2016; Dagiené, Stupuriene and Vinikiene, 2017).

\section{Computation is an increasingly essential tool}

The abilities that computational thinking can provide are really valuable for all citizens, and not only for informatics professionals. Computational thinking is strategically important for dealing with many kinds of problems, and can be specially useful in mathematics, science, and engineering, where models, simulation, experiments are primary learning asset (Dagienè and Stupuriene, 2016).

CT is a type of analytical thinking that employs mathematical and engineering thinking to understand and solve complex problems within the constraints of the real world. The term was first used by S. Papert (1996), who is widely known for the development of the Logo software. However, it was brought to the forefront of the computer society by Wing (2006) to describe how to think like a computer scientist. She described CT as "solving problems, designing systems and understanding human behavior by drawing on the concepts fundamental to computer science".

\section{Computational Thinking}

The main characteristics of CT include:

- Analyzing and logically organizing data.

- Data modeling, data abstractions, and simulations.

- Formulating problems such that computers may assist.

- Identifying, testing, and implementing possible solutions.

- Automating solutions via algorithmic thinking.

- Generalizing and applying this process to other problems.

Teachers acknowledge the need to teach computational thinking but may struggle with the various and conflicting interpretations of its nature. This may be the result of debate by individuals and groups (Computer Science Teachers Association (CSTA), 2011; Henderson, Cortina and Wing, 2007; Lu and Fletcher, 2009; Naughton, 2012; Wing, 2006; Wing, 2008; Yadav, Zhou, Mayfield, Hambrusch and Korb, 2011) concerning what is and is not computational thinking. Once computational thinking is defined adequately, appropriate assessment instruments can be designed and we follow this last definition, that is, a more defined expression of CT in order to fit better with the practices of a class (Kalelioğlu, Gülbahar and Kukul, 2016; Román-González, MorenoLeón and Robles, 2017).

Liu and Wang (2010) defined computational thinking as a hybrid of other modes of thinking, like abstract thinking, logical thinking, modeling thinking, and constructive thinking. In this way, they include the main characteristics of CT. For example, abstract thinking is essential in computer science and technology. 
Logical thinking is the process in which one uses reasoning consistency to come to a conclusion.

Modeling thinking, in the technical use of the term, refers to the translation of objects or phenomena from the real world into mathematical equations (mathematical models) or computer relations (simulation models).

Constructive thinking is any well-defined computational procedure that takes some value, or set of values as input and produces some value, or set of values as output.

\section{Relation with ICT and Computer Science}

Computer Science and ICT (Information and Communication Technology) are generally recognized as very important issues at all levels of Education. Digital Agenda for Europe (European Commission, 2010) includes them as Pillar VII "ICT-enabled benefits for EU society".

In 2006 the European Parliament and the Council (European Parliament and the Council, 2006) published a recommendation identifying eight Key Competences for Lifelong Learning: Communication in the Mother Tongue; Communication in Foreign Languages; Mathematical Competence and Basic Competences in Science and Technology; Digital Competence; Learning to Learn; Social and Civic Competences; Entrepreneurship; and Cultural Awareness and Expression. Four years afterwards, the value of this recommendation is recognized in the Europe 2020 Strategy (European Commission, 2010).

The needed skills are seen as the ability to manage information; the capacity to distinguish the virtual from the real world and to see the connections between these two domains; the ability to use Internet-based services and to use technologies to support critical thinking, creativity and innovation.

Different reports and research papers argue about promoting the inclusion of Computational Thinking (CT) in education and the pervasiveness of technologies, which leads to the subsequent need to acquire Digital Competence to be functional in our knowledge society; digital inclusion depends more on knowledge and skills than on access and use (Eshet-Alkalai, 2004). Computer-related proficiency is the key to employability and improved life chances (Sefton-Green, Nixon and Erstad, 2009).

According to OECD (2010), "education standards need to include the kind of skills and competences that can help students become responsible and performing users of technology and to develop the new competences required in today's economy and society which are enhanced by technology, in particular those related to knowledge management".

Recently, Mark Guzdial (2015) has argued that Computational Thinking as it was descript by Wing was not plausible. He maintains that the idea of learning computing will not impact everyday thinking and problem-solving, but he agrees with the idea that computing providing a medium for advancing thinking and learning in other domains (he called it computational literacy). 


\section{Assessment of the Computational Thinking}

The Computing Progression Pathways (Dorling \& Walker, 2014) is an example of a non-statutory assessment framework. It was produced by a small team of authors and reviewers, all teachers, based on their classroom experiences. It is an interpretation of the breadth and depth of the content in the 2014 national curriculum for computing program of study.

The key to developing a framework lies in understanding that computational thinking concepts can be demonstrated in multiple ways and because it can be applied for multiple matters, subjects or areas.

Final aim is to assess the implementation of CT in school. Therefore, we follow three different but inter-connected groups of assessments: CT competences, attitudes and used definitions (vocabulary). In any body of a task we can link some part of the body with CT characteristics and measure them.

The competences of the CT that we apply are the following:

- Formulating problems in a way that enables us to use a computer and other tools to help solve them.

- Logically organizing and analyzing data.

- Representing data through abstractions such as models and simulations.

- Automating solutions through algorithmic thinking (a series of ordered steps).

- Identifying, analyzing, and implementing possible solutions with the goal of achieving the most efficient and effective combination of steps and resources.

- Generalizing and transferring this problem-solving process to a wide variety of problems.

These competences are supported and enhanced by a number of dispositions or attitudes that are essential dimensions of CT. These dispositions or attitudes include:

- Confidence in dealing with complexity.

- Persistence in working with difficult problems.

- Tolerance for ambiguity.

- The ability to deal with open-ended problems.

- The ability to communicate and work with others to achieve a common goal or solution.

Vocabulary (and definitions) of the CT that can be used in a task:

- Data Collection: the process of gathering appropriate information.

- Data Analysis: Making sense of data, finding patterns, and drawing conclusions.

- Data Representation: Depicting and organizing data in appropriate graphs, charts, words, or images.

- Problem Decomposition: Breaking down tasks into smaller, manageable parts.

- Abstraction: Reducing complexity to define main idea.

- Algorithms and Procedures: Series of ordered steps taken to solve a problem or achieve some end. 
- Automation: Having computers or machines do repetitive or tedious tasks.

- Simulation: Representation or model of a process. Simulation also involves running experiments using models.

- Parallelization: Organize resources to simultaneously carry out tasks to reach a common goal.

As a simple but clear example, imagine that we ask our students to do the next task:

We draw a rectangle in a squared sheet. Our rectangle contains inside several small squares (of the squared sheet). Deduce how the area of the rectangle is calculated based on the lengths of the base and height and express it through a single formula.

Solution is obvious: Base $\mathrm{x}$ Height. Relation of the body of the task and CT is shown in Table 1.

Table 1. Example of competences, attitudes and concepts.

\begin{tabular}{|l|l|l|}
\hline \multicolumn{1}{|c|}{ CT competences } & \multicolumn{1}{|c|}{ CT attitudes } & \multicolumn{1}{c|}{ CT concepts } \\
\hline \multicolumn{2}{|c|}{ "Based on the lengths of the base and height" } \\
\hline $\begin{array}{l}\text { - Logically organizing and } \\
\text { analyzing data }\end{array}$ & $\begin{array}{l}\text { - Confidence in dealing with } \\
\text { complexity }\end{array}$ & $\begin{array}{l}\text { - Data analysis } \\
\text { - Data representation }\end{array}$ \\
\hline \multicolumn{3}{|c|}{ "Deduce how the area is calculated" } \\
\hline $\begin{array}{l}\text { - Representing data through } \\
\text { abstractions such as models and } \\
\text { simulations }\end{array}$ & $\begin{array}{l}\text { - The ability to deal with open- } \\
\text { ended problems }\end{array}$ & - Abstraction \\
\hline \multicolumn{2}{|c|}{ "Express it through a single formula" } \\
\hline $\begin{array}{l}\text { - Formulating problems in a way } \\
\text { that enables us to use a computer } \\
\text { and other tools to help solve them }\end{array}$ & - Tolerance for ambiguity & $\begin{array}{l}\text { - Algorithms and } \\
\text { procedures } \\
\text { - Automation }\end{array}$ \\
\hline
\end{tabular}

We use for evaluation of these three inter-connected groups (competences, attitudes and concepts) a model based on rubrics, where teacher must fill in a table, with marks, following a list of questions that lead teacher to assess the three groups of the CT.

\section{Conclusion}

In the next future people that will not have a minimum knowledge about technology will have serious problems to develop their professional career. There is a ubiquity of computers and microprocessors in our lives and it affects both to the economy and future jobs and to the education of future citizens. Almost all fields of innovation are related to computing in some way. And the necessity of knowledge in computing is essential in the global economy market, being a basic tool for competition. Computational Thinking is a new and fundamental way of thinking and problem solving, described as a way for solving problems, designing systems and understanding human behavior by drawing on the concepts fundamental to computer science. 
This collection of various skills to do with problem solving that result from studying the nature of computation is even claiming by some experts that it should be added to reading, writing and arithmetic as a core ability that every person should learn. One way of assessment of this application of CT in the pre-university education system is presented, classifying CT measurements in three groups: competences, attitudes and concepts.

\section{References}

Computer Science Teachers Association Task Force (2011). K-12 Computer Science Standards, New York, ACM.

Dagiené, V., Stupuriene, G. (2016). Bebras - a Sustainable Community Building Model for the Concept Based Learning of Informatics and Computational Thinking. Informatics in Education, Vol. 15, No. 1, 25-44.

Dagienè, V., Stupuriene, G., Vinikiene, L. (2017). Implementation of Dynamic Tasks on Informatics and Computational Thinking. Baltic Journal of Modern Computing, Vol. 5, No. 3, 306-316.

Dorling, M., Walker, M. (2014). Computing Progression Pathways, available at https://www.hoddereducation.co.uk/Compute-IT/ProgressionPathwaysGrid.

Eshet-Alkalai, Y. (2004). Digital Literacy. A Conceptual Framework for Survival Skills in the Digital Era. Journal of Educational Multimedia \& Hypermedia, 13(1), 93-106.

European Commission (2010). Europe 2020: A strategy for smart, sustainable and inclusive growth, COM (2010) 2020.

European Parliament and the Council (2006). Recommendation of the European Parliament and of the Council of 18 December 2006 on key competences for life-long learning. Official Journal of the European Union, L394/310.

Guzdial, M. (2015). Learner-Centered Design of Computing Education: Research on Computing for Everyone. Synthesis Lectures on Human-Centered Informatics, November 2015, Vol. 8, No. 6 , 1-165, ISBN-13: 978-1627053518.

Henderson, P.B., Cortina, T.J., Wing, J.M. (2007). Computational Thinking. Proceedings of the 38th SIGCSE technical symposium on Computer science education. Covington, Kentucky, USA: ACM.

Kalelioğlu, F., Gülbahar, Y., Kukul, V. (2016). A framework for computational thinking based on a systematic research review. Baltic Journal of Modern Computing, Vol. 4, No. 3, 583-596.

Liu, J., Wang, L. (2010). Computational Thinking in Discrete Mathematics. IEEE 2nd International Workshop on Education Technology and Computer Science, 413-416.

Lu, J.J., Fletcher, G.H.L. (2009). Thinking About Computational Thinking. In: Proceedings of the 40th ACM Technical Symposium on Computer Science Education, 2009 Chattanooga, TN, USA. New York: ACM, 260-264.

National Research Council (2010). Report of a Workshop on the Scope and Nature of Computational Thinking. The National Academies Press.

Naughton, J. (2012). Why All Our Kids Should Be Taught How to Code. The Guardian, available at http://www.theguardian.com/education/2012/mar/31/why-kids-should-be-taught-code.

OECD (2010). Are the New Milleniums Learners Making the Grade? Technology use and educational performance in PISA (2010). OECD.

Papert, S. (1996). An exploration in the space of Mathematics Education. International Journal of Computers for Mathematics, Vol. 1, No. 1, 95-123.

Román-González, M., Moreno-León, J., Robles, G. (2017). Complementary Tools for Computational Thinking Assessment, CTE 2017, Hong-Kong.

Sefton-Green, J., Nixon, H., Erstad, O. (2009). Reviewing Approaches and Perspectives on "Digital Literacy". Pedagogies: An International Journal, 4, 107-125. 
Weintrop, D., Beheshti, E., Horn, M., Orton, K., Jona, K., Trouille, L., Wilensky, U. (2016). Defining Computational Thinking for Mathematics and Science Classrooms. J Sci Educ Technol, Vol. 25, No. 1, 127-147.

Weiser, M. (1991). The Computer for the Twenty-First Century, Scientific American, Sept. 1991, 94-10.

Weiser, M. (1993). Hot Topics: Ubiquitous Computing, Computer, Oct. 1993.

Wing, J.M. (2006). Computational thinking. Communications of the ACM, 49(3), 33-35.

Wing, J. (2008). Computational Thinking and Thinking About Computing. Philosophical Transactions of The Royal Society A, 366, 3717-3725.

Yadav, A., Zhou, N., Mayfield, C., Hambrusch, S., Korb, J.T. (2011). Introducing Computational Thinking in Education Courses. Proceedings of the 42nd ACM technical symposium on Computer science education. Dallas, TX, USA: ACM.

Received October 21, 2017, accepted November 28, 2017 